
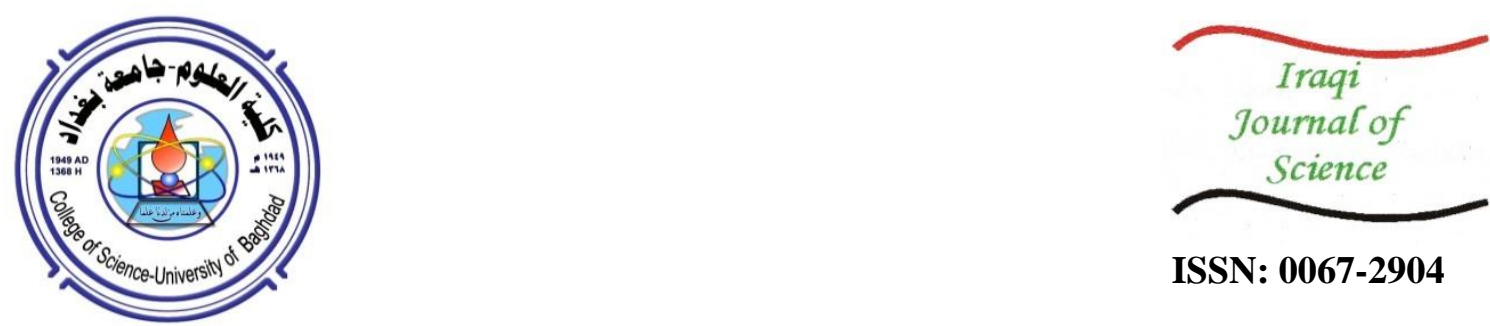

ISSN: 0067-2904

\title{
The Stress-Inducible Heat Shock Protein 70 (HSPA1A) as A Novel Biomarker in Lung Tumors: A Promoting Study
}

\author{
Zainab M. Lateef ", Alice K. Melconian, Ehab D. Salman \\ Department of Biotechnology, College of Sciences, University of Baghdad
}

Received: $1 / 12 / 2020$

Accepted: 19/1/2021

\begin{abstract}
Heat shock proteins (HSPs) are a group of intracellular proteins that promote proteins folding and unfolding under normal and/or stress conditions. In addition to their intracellular location, HSPs are found on the plasma membranes of stressed, but not normal, cells and in the extracellular milieu where they can trigger an immune response. For instance, the inducible form of heat shock protein 70 (HSPA1A) was found to be overexpressed, intra or extracellularly, by many types of stressed cells. In our study, we aim to investigate the levels of HSPA1A in the serum of untreated lung tumor patients and its expression in the tissues derived from lung tumors and chronic obstructive pulmonary diseases (COPD) and healthy tissues. Analyses of serum and tissue samples were performed by utilizing ELISA assay and immunohistochemical staining, respectively. The results showed significant differences in the mean levels of serum HSPA1A of the patients $(1.66 \pm 0.165)$ as compared to healthy control $(0.938 \pm 0.330)$. Significant differences were also found between these levels in the serum of smoker and nonsmoker patients $(2.006 \pm 0.342$ and $1.353 \pm 0.067$, respectively). The protein levels in the patient's serum were also found to be $29.5 \%$ correlated to smoking history. No significant differences were found in terms of gender and age within the two groups of patients and healthy volunteers. Our results showed HSPA1A protein levels to be correlated to gender $(13.5 \%)$ and age in patients and healthy volunteers (14.8\% and $0.4 \%$, respectively). In the tissues of the clinicopathological groups, HSPA1A was found to be overexpressed in benign $(I R S=8.5)$ and malignant tumors $(I R S=8.9)$ in comparison with both COPD $(I R S=4.4)$ and healthy tissues $(I R S=0.00)$. Our pilot results could support the suggestion of HSPA1A as a novel biomarker in lung tumors, as proposed by previous studies.
\end{abstract}

Keywords: heat shock proteins, HSPA1A, lung tumors, ELISA, immunohistochemistry

\section{بروتين الصدمة الحرارية 70 المحفَز(HSPA1A) كمعلم حيوي جديد في الاورام الرئوية : دراسة داعمة}

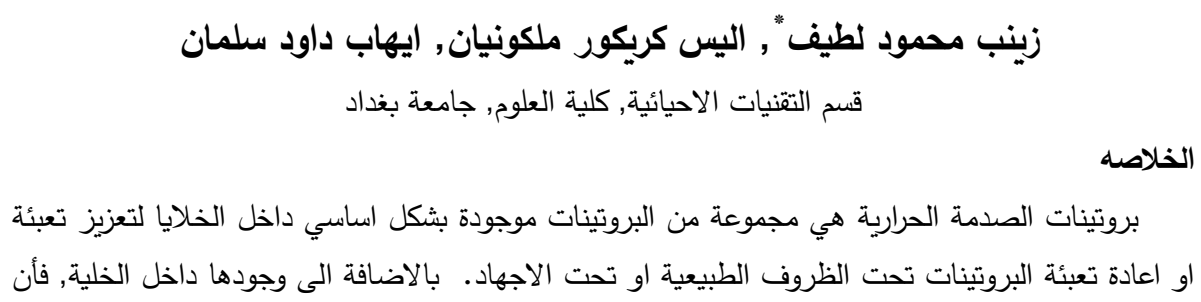




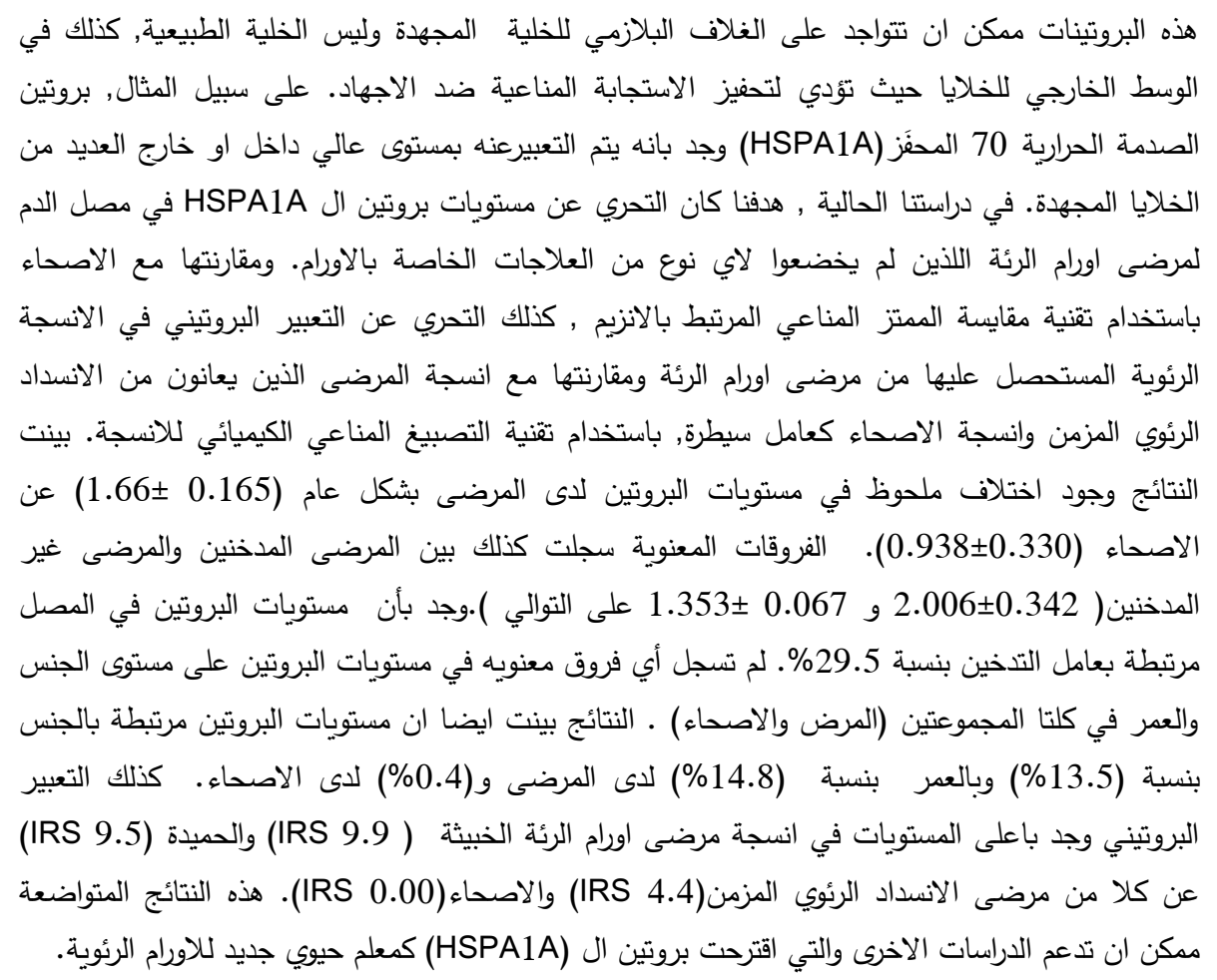

\section{Introduction}

Heat shock proteins (HSPs) are molecular chaperones with intracellular roles in proteins folding during synthesis or upon cellular stress. They prevent the aggregation of, and eliminate, incorrectly folded proteins [1]. Under stress conditions, such as high temperature, infections, and inflammation, the levels of expression are further elevated [2]. In certain cancers, intracellular HSPs have also been shown to accumulate to a high level [3]. In addition to the intracellular chaperon function, HSPs are also known to play important roles in cell pathophysiology as extracellular signaling ligands [4].

Heat shock protein 70 family (HSP70) includes the most conserved proteins in evolution, which play different roles depending on their associated targets and localization (intra or extracellularly) [5]. The inducible form of heat shock protein 70 (HSPA1A, Hsp70) is an intracellular chaperone, promoting protein folding and mostly overexpressed in different tumor types, such as lung, breast, brain, and colon cancer [6]. HSPA1A can be transported via lipid vesicular transport to the plasma membrane of the tumor cells [7]. Membrane Hsp70-positive tumors have been shown to actively release Hsp70 extracellularly in exosomes [8, 9]. Extracellular Hsp70 comes from two main sources; the exosomal Hsp70, which is released by viable membrane Hsp70-positive tumor cells, and free Hsp70, which originates from lysed cells and is released into the tissue milieu [10]. By binding to macrophage receptors, free Hsp70 is reported to elucidate inflammatory immune responses [11]. Membrane-bound Hsp70 is a tumor-specific phenomenon since it is not expressed in normal cells. It serves as a specific target for activated natural killer $(\mathrm{NK})$ cells $[12,13]$. On the other hand, to promote anti-apoptotic activities, tumorigenicity, or the overall cancer cell survival, a behave decided by specific signaling pathway $[14,15]$.

Lung cancer is one of the most common malignancies in the world. It lacks specific symptoms, which limits the opportunities to diagnose it at early stages, while most patients are diagnosed in advanced stages. Long-term early-stage tumor management and therapy may be achieved through radical surgery and radiotherapy, while at advanced stages, the treatment options are limited [16]. Recently, the immunotherapeutic approaches focus on the detection of tumor-specific characteristics that may function as tumor-specific targets. However, several 
studies are still attempting to select the biomarkers with the potential of predicting treatment response as well as to improve antitumor immune system response [17].

In this scope, several studies evaluated HSPA1A as a tumor-specific target and suggested it as a new biomarker in hepatocellular carcinoma (HCC), lung, head, and neck cancer [18-20]. In our study, we investigate the levels of HSPA1A protein in the serum of patients who yet to be detected as lung tumors patients and have not taken any type of therapy, and compared it with the serum of healthy volunteers as control. Also, we investigate HSPA1A expression in lung tissues of these patients and compare it with healthy and chronic obstructive pulmonary diseases (COPD) derived tissues.

\section{Methods}

\section{Patients and healthy volunteers enrolled in this study}

A total of 30 patients with lung tumors, 21 males and 9 females at ages from 15 to 80 years, were enrolled in our clinical study. From each patient, a lung biopsy and blood specimen were taken. A total of 20 healthy volunteers, 8 males and 12 females with age ranged from 14 to 43 years, participated in this study. Patients with chronic obstructive pulmonary diseases (COPD) and underwent lung surgery were 6 males and 1 female, ages ranged from 17 to 47 years. From each patient, a lung biopsy was taken for further analysis by immunohistochemistry (IHC).

The exclusion criteria included patients who were suffering from chronic diseases other than pulmonary one, liver diseases, kidney failure, and heart diseases. All patients enrolled in our study have never been submitted to any radio or chemotherapy before or recorded as glucocorticoid-drugs users. All patients were informed and consent was obtained before the start of the study.

\section{Serum samples}

Blood samples were collected into gel- tubes. After collection, samples were left to clot for 30 minutes at room temperature. Then, samples were centrifuged at 2,000 rpm for 20 minutes. Serum samples were stored at $-20{ }^{\circ} \mathrm{C}$ for further analysis.

\section{Lung biopsy samples}

Lung biopsies were collected from lung-tumor patients $(n=30)$, COPD patients $(n=7$; six males and one female; ages ranged from 17 to 47 years), and healthy lung tissues $(n=2)$. Each lung biopsy was collected under a sterilized condition and fixed with formalin for further examination by immunohistochemistry staining.

\section{Biochemical analysis}

The concentration of HSPA1A was measured by quantitative sandwich enzyme-linked immunosorbent assay (ELISA) using Human HSPA1A ELISA Kit (SL3006Hu SunLong Biotech Co.), which is used to evaluate the levels of HSPA1A protein in any human biological fluid including serum. Before analysis, both serum samples and kit components were warmed at room temperature. Standards or samples were diluted each with its special diluent, added to the appropriate microelisa stripplate which was initially coated with human anti-HSPA1A, and incubated for $30 \mathrm{~min}$ at $37^{\circ} \mathrm{C}$, then washed for 5 times with washing buffer. Horseradish peroxidase (HRP)-conjugated antibody specific for HSPA1A was added to the wells, which were sealed with a closure plate membrane and incubated for $30 \mathrm{~min}$ at $37^{\circ} \mathrm{C}$. Free components were discarded. The TMB substrates $\left(\mathrm{H}_{2} \mathrm{O}_{2}\right.$ and TMB) solution was added to wells, which were then incubated for 15 minutes at $37{ }^{\circ} \mathrm{C}$. The final step of the reaction was accomplished by the addition of the stop solution. The color of wells that hold HSPA1A and HRP-conjugated HSPA1A antibody only changed from blue to yellow. The optical density (OD) was measured spectrophotometrically at a wavelength of $450 \mathrm{~nm}$. HSPA1A concentration in the unknown samples was evaluated proportionally by comparing the OD of the samples to the standard curve. 


\section{Immunohistochemical staining}

Immunohistochemical staining was achieved on formalin- fixed, paraffin-embedded specimens. Following the routine staining procedure and recommendations provided by kits manufacturers, lung tissues were dewaxed and hydrated with three changes of xylene and a series of graded alcohols to water, heated in a microwave for $30 \mathrm{~min}$ in retrieval solution, then washed for 5 min in H2O. Specimens were washed twice with TPBS buffer and incubated with $\mathrm{H}_{2} \mathrm{O}_{2}$ for 5-10 minutes to block peroxidase enzyme activity. Specimens were then incubated with diluted rabbit primary antibody (CSB-PA556911,Cusabio Technology, China), followed by incubation with the HRP-labeled polymer (PathnSitu, USA) for 30 minutes. Staining was completed by 15 minutes incubation with 3,3-diaminobenzidine (DAB) substrate-chromogen (PathnSitu OSH001) which resulted in a brown-colored precipitate at the antigen site.

Intensity of staining was classified from 0 to 3 , where $0(-)$ is negative, $1(+)$ is low or weak, $2(++)$ is moderate, and $3(+++)$ is high or strong. The extent of staining, referred to as the percentage of positive cells relative to the whole tumors, was classified into five grades: 0 (0\%), 1 (1-25\%), 2 (26-50\%), $3(51-75 \%)$, and 4 (76-100\%). The overall staining interpretation is given as immunoreactive score (IRS), which was estimated through the formula:

IRS $=$ percentage score $\times$ intensity score $\quad$ (ranged from $0-12$ )

IRS was adopted to compare the expression of protein among different clinicopathologic groups and/or control.

\section{Statistical analysis}

Data analysis was performed by using Statistical Package for the Social Sciences (SPSS) version 21. All variables are presented as mean \pm standard error of the mean (SEM). The association between dependent and independent variables is presented as a percentage, calculated in relation to Eta values. One way analysis of variance (ANOVA) analysis was used for comparison between groups. Two-tailed p-value $<0.05$ was considered as statistically significant.

\section{Results}

\section{Heat shock protein 70 levels in serum}

A total of 30 patients with lung tumors at different ages were enrolled in our clinical study. From each patient, a blood specimen was taken. A total of 20 healthy volunteers participated in this experiment, whose blood samples were used as control. According to ELISA test results, patients with lung tumors had a significant higher mean level of serum HSPA1A $(1.66 \pm 0.165)$ compared with healthy control $(0.938 \pm 0.330)$ at $p$-value $<0.001$, as shown in Figure 1. Significant differences were also found in the mean values of the protein concentrations in the serum of smoker and nonsmoker patients $(2.006 \pm 0.342$ and $1.353 \pm$ 0.067 , respectively; Figure 2). The protein levels in the patient's serum were also found to be $29.5 \%$ correlated to smoking history. The results also revealed no significant differences in the mean of protein levels in terms of gender (Figure 3-A) and age (Figure 3-B) within the two groups of patients and healthy volunteers. Our results also showed that HSPA1A protein levels are correlated to gender $(13.5 \%)$ and age in patients and healthy volunteers $(14.8 \%$, and $0.4 \%$, respectively). 


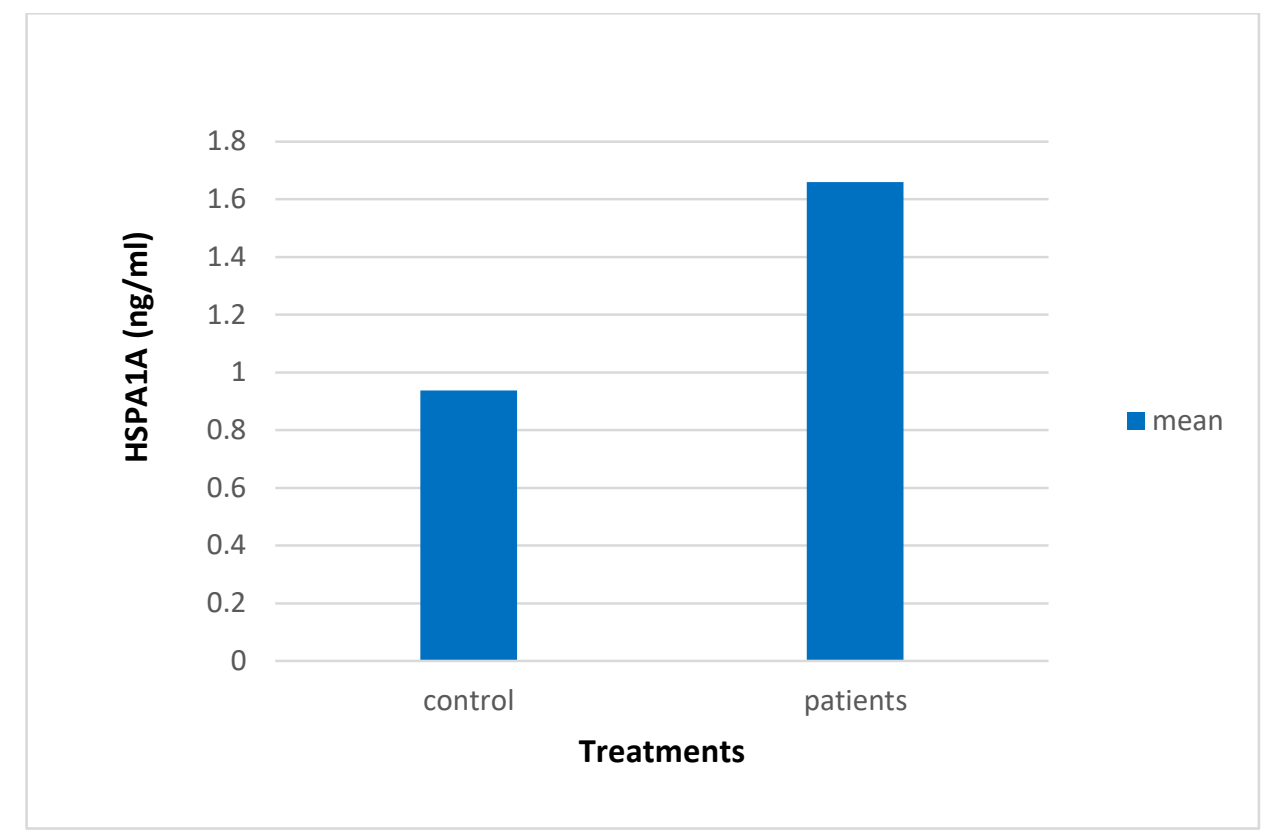

Figure 1-Heat shock protein 70 (HSPA1A) mean concentration $(\mathrm{ng} / \mathrm{ml})$ in serum of healthy control and lung tumor patients, P-value $<0.001$.

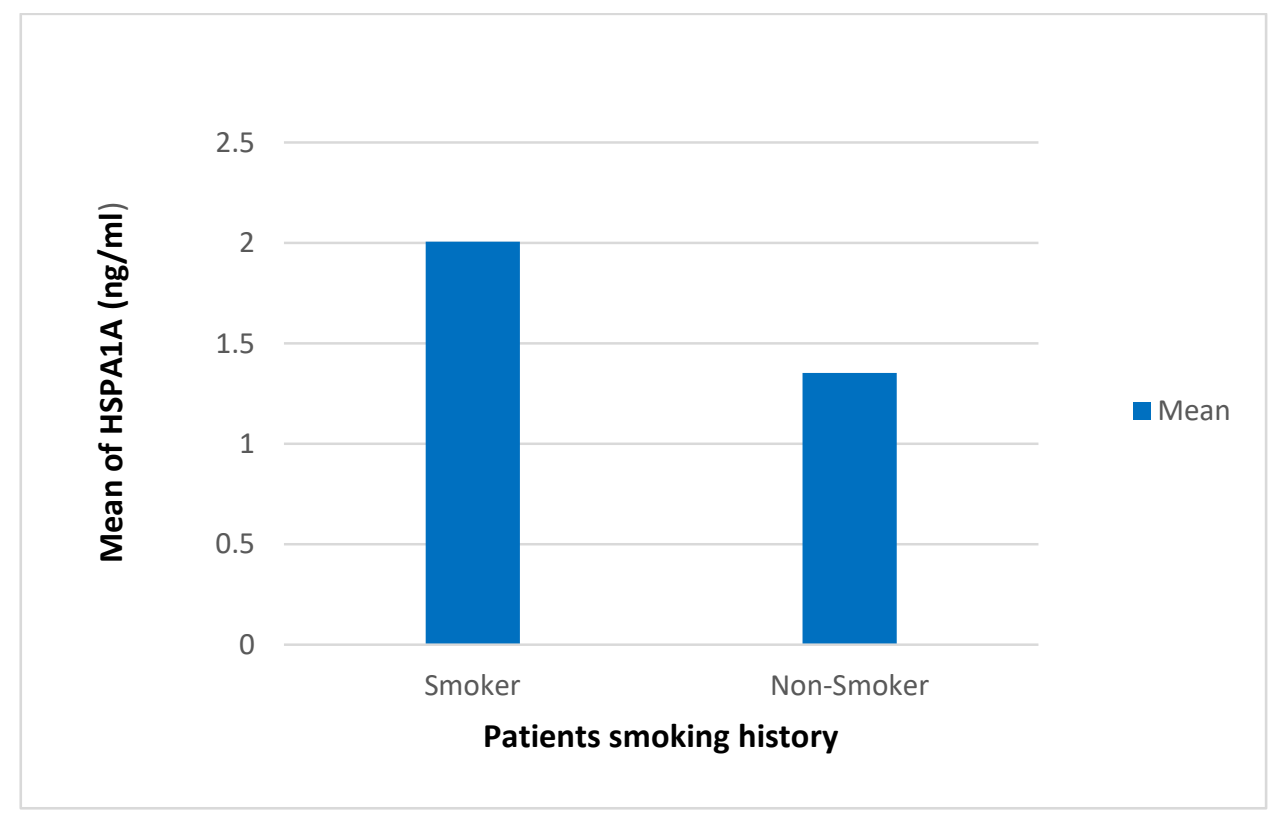

Figure 2- The mean concentration (ng/ml) of heat shock protein 70 (HSPA1A) in serum of smoker and non-smoker lung tumor patients. P-value $<0.049$. 

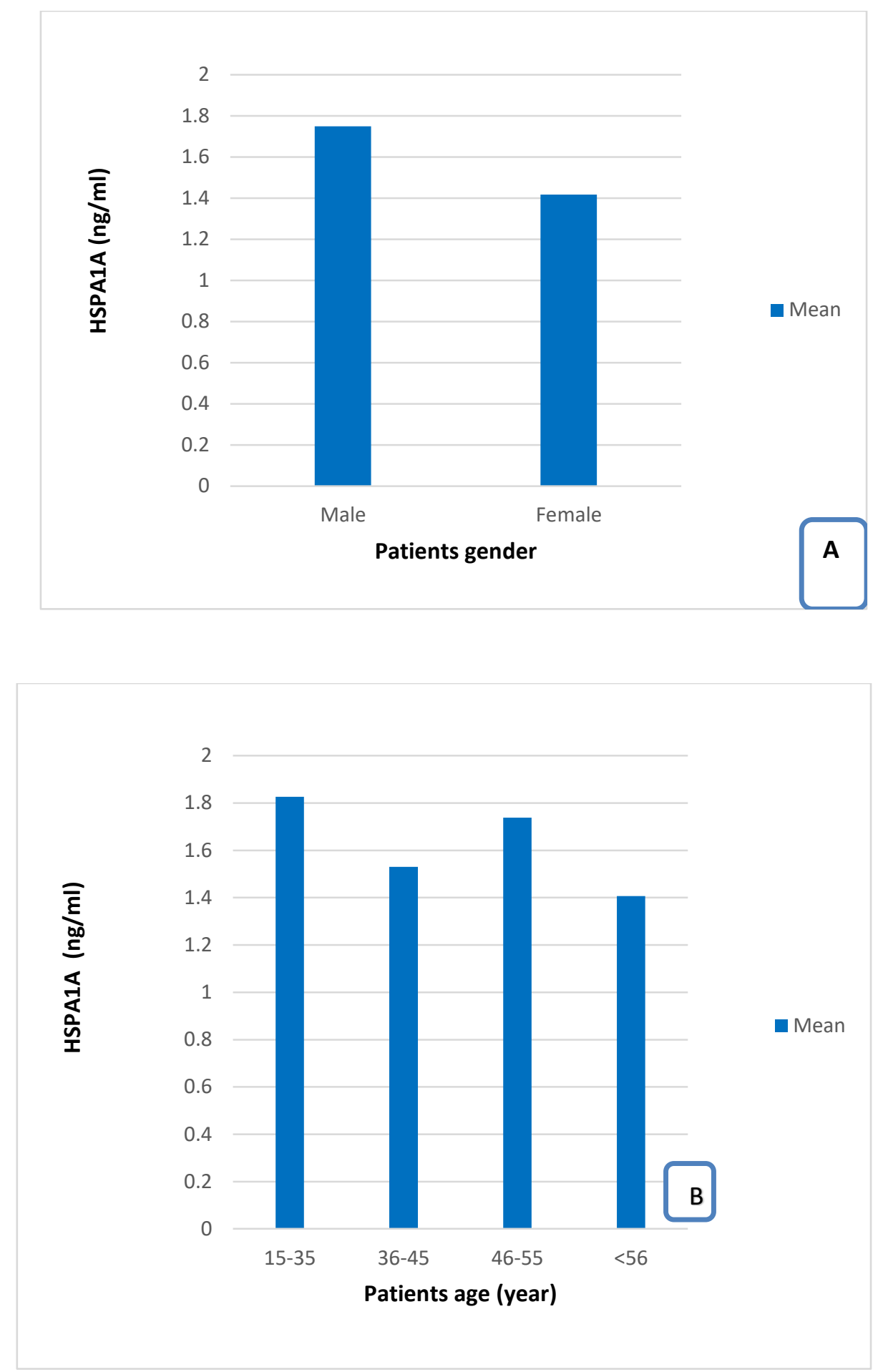

Figure 3-The mean concentration $(\mathrm{ng} / \mathrm{ml})$ of HSPA1A in serum of lung tumor patients according to: A: gender P-value 0.352. B: ages; P-value 0.824 . 


\section{Immunohistochemical staining of lung tissues}

Immunohistochemical staining was achieved on formalin-fixed, paraffin-embedded specimens. The overall staining interpretation is given as immunoreactive score (IRS) and is adopted to compare the expression of protein among different clinicopathologic groups and control. The results show that protein expression increased significantly in malignant tissues (8.9 $\pm .0 .66)$, benign tissues $(8.464 \pm 0.89)$, and COPD- derived tissues $(4.4 \pm 0.61)$ compared with healthy tissue $(0.00 \pm 0.00)$ at p-value $\leq 0.008$, as shown in Figure 4 . Data analysis revealed that IRS score is correlated to clinicopathologic phenotypes as follows: $585 \%$ in malignant tumors, $662 \%$ in benign tumors, and $214 \%$ in COPD patients.

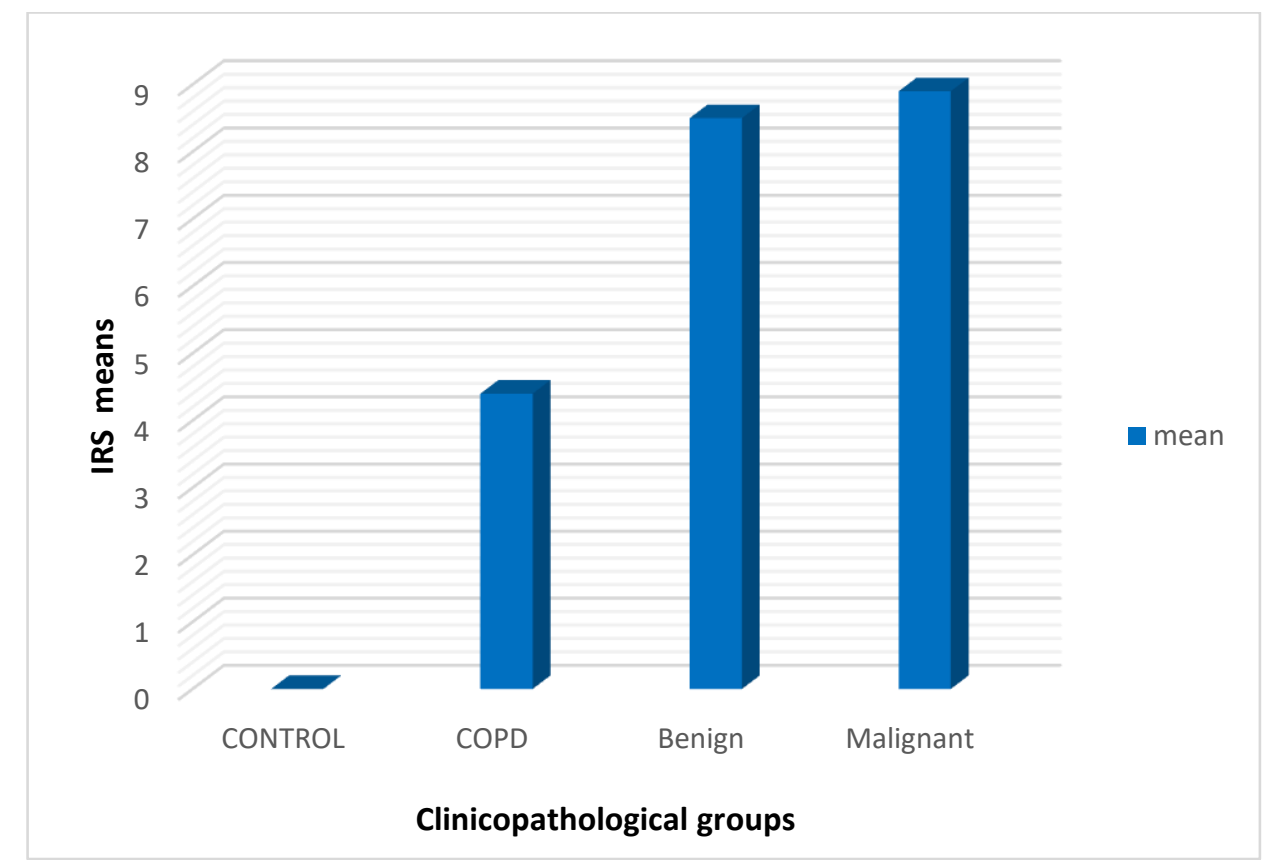

Figure 4-The expression of HSPA1A protein in lung tissues. Comparisons are made depending on the means of overall immunoractive score (IRS) in lung tissues derived from malignant and benign tumors patients, COPD patients, and control. P-value 0.008.

Data analysis also shows, when comparing protein expression within clinicopathological groups, a significant difference in the expression of HSPA1A in COPD tissues as compared to malignant ( $\mathrm{p}$-value 0.001 ) and benign tissues ( $\mathrm{p}$-value 0.004 ). In addition, no differences were observed between the expression in malignant and benign tumors ( $p$-value 0.657), as illustrated in Table 1. 
Table 1-A comparison of HSPA1A protein expression within clinicopathological groups. Different superscript letters indicate significant differences between means listed in the same column.

\begin{tabular}{|c|c|c|c|c|c|}
\hline \multirow{2}{*}{ (I) Treatment } & \multirow{2}{*}{ (J) Treatment } & \multirow{2}{*}{ Mean \pm S.E } & \multirow{2}{*}{ Sig. } & \multicolumn{2}{|c|}{ 95\% Confidence Interval } \\
\hline & & & & Lower Bound & Upper Bound \\
\hline \multirow{2}{*}{ Patient with Malignant } & Patient with Benign & $0.4627^{\mathrm{A}} \pm 1.0343$ & 0.657 & -1.639 & 2.565 \\
\hline & Patient with COPD & $4.5406^{\mathrm{B}} \pm 1.2070$ & 0.001 & 2.088 & 6.993 \\
\hline \multirow{2}{*}{ Patient with Benign } & Patient with Malignant & $0.4627^{\mathrm{A}} \pm 1.0343$ & 0.657 & -2.565 & 1.639 \\
\hline & Patient with COPD & $4.0779^{\mathrm{B}} \pm 1.3199$ & 0.004 & 1.396 & 6.760 \\
\hline \multirow{2}{*}{ Patient with COPD } & Patient with Malignant & $4.5406^{\mathrm{B}} \pm 1.2070$ & 0.001 & -6.993 & -2.088 \\
\hline & Patient with Benign & $4.0779^{\mathrm{B}} \pm 1.3199$ & 0.004 & -6.760 & -1.396 \\
\hline
\end{tabular}

\section{Discussion}

Intracellular heat shock protein 70 (Hsp70), apart from its chaperone activity, plays a key role in cell proliferation and differentiation, by interfering with apoptosis and tumorigenesis [21]. In our study, we investigated the levels of HSPA1A in the serum of lung-tumor patients and healthy volunteers. The results showed that patients with lung tumors have significantly higher means of serum HSPA1A levels $(1.66 \pm 0.165)$ than healthy control $(0.938 \pm 0.330)$. A significant difference was also found in the means of protein concentrations in the serum of smoker and nonsmoker patients $(2.006 \pm 0.342$ and $1.353 \pm 0.067$, respectively. Results also revealed that there is no significant difference in means of protein levels in terms of gender within two groups of patients and healthy volunteers. Comparing protein expression between groups through IRS revealed a significant difference between COPD tissues as compared to malignant (p- value 0.001) and benign tissues (p-value 0.004).

Our findings come in line with Gunther et al, 2015, who reported that squamous cell and adeno non-small cell lung cancer patients (NSCLC) had higher serum Hsp70 levels than healthy individuals [19]. NSCLC patients were also reported to have higher levels of Hsp70 in the blood than COPD patients [22]. Hsp70 was shown to be induced in smokers lung, which was suggested to be a host response against the induced damage [23]. Previous work demonstrated such differences in Hsp70 serum levels in patients with inflammatory liver diseases and tumors, such as chronic hepatitis, liver cirrhosis, and hepatocellular carcinoma [18].

Previous studies also showed that Hsp70 membrane-positive tumors actively secrete Hsp70 into the extracellular microenvironment of cells, proposing its potential importance as a blood-derived biomarker [20, 22]. In patients with head and neck squamous cell carcinoma, a high expression of membranous Hsp70 on viable tumor cells was found to be associated with increased levels of circulated Hsp70 [24]. Furthermore, the elevated levels of HSPA1A were found to be related to disease levels in rheumatoid arthritis patients, suggesting it as a diagnostic tool of arthritis and for monitoring disease progress [25]. Our results disagree with 
those of Tang et al study [26] that reported a decrease in HSPA1A protein levels in lung cancer patients. However, the same study demonstrated HSPA1A as a novel biomarker to predict early stage lung cancer.

The elevated levels of HSPA1A protein in serum of lung tumor patients enrolled in our study, who never underwent any therapeutic strategy, might reflect aggressive tumor type. Another source of this protein in serum is the dying tumor cells. This, in turn, will act as an immunostimulator that induces the cytolytic activity of natural killer cells (NK), specifically against HSPA1A-positive tumor cells, as demonstrated by a previous study [27]. On the other hand, the expression of this protein, intracellularly or on the surface of tumor cells, could protect tumor cells by interfering with pro-apoptotic pathways [28].

\section{Conclusions}

Increased HSPA1A levels in lung tumor patient's serum were found, combined with differential expression in different clinicopathological tissues. These findings could support a role for Hsp70 as a potential tumor-specific biomarker that can distinguish lung inflammatory and tumor diseases. However, further researches are required to evaluate the exact role of circulating HSPA1A in the diagnosis and further prognosis of lung tumor.

\section{References}

[1] Asea, A. A., and Kaur, P. (Eds.). Regulation of heat shock protein responses (vol. 13). Springer, 2018.

[2] Pierre, M., and Rébé, C. "Heat Shock Proteins and Inflammasomes". International Journal of Molecular Sciences, vol. 20, no. 18, 2019.

[3] Lianos, G. D.; Alexiou, G. A.; Mangano, A.; Mangano, A.; Rausei, S.; Boni, L.,and Roukos, D. H. "The role of heat shock proteins in cancer". Cancer letters, vol. 360, no. 2, pp. 114-118, 2015.

[4] Pockley, A. G., and Henderson, B. "Extracellular cell stress (heat shock) proteins-immune responses and disease: an overview". Philosophical Transactions of the Royal Society B: Biological Sciences, vol. 373, no. 1738, pp. 20160522, 2018.

[5] Tsybikov, N. N.; Egorova; E. V.; Kuznik, B. I.; Fefelova; E. V., and Magen, E. "Heat Shock Protein 70 and Anti-heat Shock Protein 70 Antibodies in Nasal Secretions of Patients with Chronic Rhinosinusitis". Allergy \& Rhinology, vol. 7, no. 1, ar-2016.

[6] Pfister, K.; Radons, J.; Busch, R.; Tidball, J. G.; Pfeifer, M.; Freitag, L., and Multhoff, G. "Patient survival by Hsp70 membrane phenotype: association with different routes of metastasis". Cancer: Interdisciplinary International Journal of the American Cancer Society, vol. 110, no. 4, pp. 926935, 2007.

[7] Bayer, C.; Liebhardt, M. E.; Schmid, T. E.; Trajkovic-Arsic, M.; Hube, K.; Specht, H. M.,and Wilkens, J. J. "Validation of heat shock protein 70 as a tumor-specific biomarker for monitoring the outcome of radiation therapy in tumor mouse models". International Journal of Radiation Oncology* Biology* Physics, vol. 88, no. 3, pp. 694-700, 2014.

[8] Lv, L. H.; Wan, Y. L.; Lin, Y.; Zhang, W.; Yang, M.; Li, G. L., and Min, J. "Anticancer drugs cause release of exosomes with heat shock proteins from human hepatocellular carcinoma cells that elicit effective natural killer cell antitumor responses in vitro". Journal of Biological Chemistry, vol. 287, no. 19, pp. 15874-15885, 2012.

[9] Aneja, R.; Odoms, K.; Dunsmore, K.; Shanley, T. P., and Wong, H. R. "Extracellular heat shock protein-70 induces endotoxin tolerance in THP-1 cells". The Journal of Immunology, vol. 177, no. 10, pp. 7184-7192, 2006.

[10] De Maio, A. "Extracellular Hsp70: export and function". Current Protein and Peptide Science, vol. 15, no. 3, pp. 225-231, 2014.

[11] Calderwood, S. K.; Gong, J., and Murshid, A. "Extracellular HSPs: the complicated roles of extracellular HSPs in immunity". Frontiers in immunology, vol. 7, no. 159, 2016.

[12] Krause, S. W.; Gastpar, R.; Andreesen, R.; Gross, C.; Ullrich, H.; Thonigs, G., and Multhoff, G. "Treatment of colon and lung cancer patients with ex vivo heat shock protein 70-peptideactivated, autologous natural killer cells: a clinical phase I trial". Clinical Cancer Research, vol. 10, no. 11, pp. 3699-3707, 2004.

[13] Specht, H. M.; Ahrens, N.; Blankenstein, C.; Duell, T.; Fietkau, R.; Gaipl, U. S., and Hautmann, 
M. "Heat shock protein 70 (Hsp70) peptide activated natural killer (NK) cells for the treatment of patients with non-small cell lung cancer (NSCLC) after radiochemotherapy (RCTx)-from preclinical studies to a clinical phase II trial". Frontiers in immunology, vol. 6, no. 162, 2015.

[14] Hantschel, M., Pfister, K., Jordan, A., Scholz, R., Andreesen, R., Schmitz, G., and Multhoff, G. "Hsp70 plasma membrane expression on primary tumor biopsy material and bone marrow of leukemic patients". Cell stress \& chaperones, vol. 5, no. 5, pp. 438, 2000.

[15] Aghdassi, A., Phillips, P., Dudeja, V., Dhaulakhandi, D., Sharif, R., Dawra, and Saluja, A. "Heat shock protein 70 increases tumorigenicity and inhibits apoptosis in pancreatic adenocarcinoma". Cancer research, vol. 67, no. 2, pp. 616-625, 2007.

[16] Guckenberger, M., Allgäuer, M., Appold, S., Dieckmann, K., Ernst, I., Ganswindt, U., and Sterzing, F. "Safety and efficacy of stereotactic body radiotherapy for stage I non-small-cell lung cancer in routine clinical practice: a patterns-of-care and outcome analysis". Journal of Thoracic Oncology, vol. 8, no. 8, pp. 1050-1058, 2013.

[17] Gnjatic, S., Bronte, V., Brunet, L. R., Butler, M. O., Disis, M. L., Galon, J., and Kirkwood, J. M. "Identifying baseline immune-related biomarkers to predict clinical outcome of immunotherapy". Journal for immunotherapy of cancer, vol. 5, no. 1, pp. 1-18, 2017.

[18] Gehrmann, M., Cervello, M., Montalto, G., Cappello, F., Gulino, A., Knape, C., and Multhoff, G. "Heat shock protein 70 serum levels differ significantly in patients with chronic hepatitis, liver cirrhosis, and hepatocellular carcinoma". Frontiers in immunology, vol. 5, no. 307, 2014.

[19] Gunther, S., Ostheimer, C., Stangl, S., Specht, H. M., Mozes, P., Jesinghaus, M., and Multhoff, G. "Correlation of Hsp70 serum levels with gross tumor volume and composition of lymphocyte subpopulations in patients with squamous cell and adeno non-small cell lung cancer". Frontiers in immunology, vol. 6, no. 556, 2015.

[20] Kleinjung, T., Arndt, O., Feldmann, H. J., Bockmühl, U., Gehrmann, M., Zilch, T., and Rossbacher, L. "Heat shock protein 70 (Hsp70) membrane expression on head-and-neck cancer biopsy - a target for natural killer (NK) cells". International Journal of Radiation Oncology* Biology* Physics, vol. 57, no. 3, pp. 820-826, 2003.

[21] Dakappagari, N., Neely, L., Tangri, S., Lundgren, K., Hipolito, L., Estrellado, A., and Zhang, H. "An investigation into the potential use of serum Hsp70 as a novel tumour biomarker for Hsp90 inhibitors". Biomarkers, vol. 15, no. 1, pp. 31-38, 2010.

[22] Zimmermann, M., Nickl, S., Lambers, C., Hacker, S., Mitterbauer, A., Hoetzenecker, K., Rozsas, A., Ostoros, G., Laszlo, V., Hofbauer, H. and Renyi-Vamos, F., "Discrimination of clinical stages in non-small cell lung cancer patients by serum HSP27 and HSP70: A multi-institutional casecontrol study". Clinica Chimica Acta, vol. 413, no. 13-14, pp.1115-1120, 2012.

[23] Newkirk, M. M., Mitchell, S., Procino, M., Li, Z., Cosio, M., Mazur, W., and El-Gabalawy, H. S. "Chronic smoke exposure induces rheumatoid factor and anti-heat shock protein 70 autoantibodies in susceptible mice and humans with lung disease". European journal of immunology, vol. 42, no. 4, pp. 1051-1061, 2012.

[24] Gehrmann, M., Specht, H. M., Bayer, C., Brandstetter, M., Chizzali, B., Duma, M., .and Sage, E. "Hsp70-a biomarker for tumor detection and monitoring of outcome of radiation therapy in patients with squamous cell carcinoma of the head and neck". Radiation oncology, vol. 9, no. 1, pp. 131, 2014.

[25] Najafizadeh, S. R., Ghazizadeh, Z., Nargesi, A. A., Mahdavi, M., Abtahi, S., Mirmiranpour, H., and Nakhjavani, M. "Analysis of serum heat shock protein 70 (HSPA1A) concentrations for diagnosis and disease activity monitoring in patients with rheumatoid arthritis". Cell Stress and Chaperones, vol. 20, no. 3, pp. 537-543, 2015.

[26] Tang, T., Yang, C., Brown, H. E., and Huang, J. "Circulating heat shock protein 70 is a novel biomarker for early diagnosis of lung cancer". Disease Markers, 2018.

[27] Gastpar, R., Gehrmann, M., Bausero, M. A., Asea, A., Gross, C., Schroeder, J. A., and Multhoff, G. "Heat shock protein 70 surface-positive tumor exosomes stimulate migratory and cytolytic activity of natural killer cells". Cancer research, vol. 65, no. 12, pp. 5238-5247, 2005.

[28] Jäättelä, M., Wissing, D., Kokholm, K., Kallunki, T., and Egeblad, M. "Hsp70 exerts its antiapoptotic function downstream of caspase-3-like proteases". The EMBO journal, vol. 17, no. 21, pp. 6124-6134, 1998. 